\title{
A chart review of acute care inter-hospital transfers from rural WV hospitals
}

Dilip Nair, MD ${ }^{1}$, Freddie Vaughan, $\mathrm{MD}^{1}$, Katherine Bennett, $\mathrm{MD}^{1}$

\section{Author Affiliations:}

1. Joan C. Edwards School of Medicine, Marshall University, Huntington, West Virginia

The authors have no conflicts of interest to disclose.

\section{Corresponding Author:}

Dilip Nair, MD

Marshall University

Joan C. Edwards School of Medicine

Huntington, West Virginia

Email: nair@marshall.edu 


\section{Abstract}

Objective

To document the characteristics of acute care patient transfers from rural West Virginia hospitals.

\section{Data Sources/Study Setting}

Hospital patient charts in rural West Virginia hospitals

\section{Design}

We examined 40 acute care patient transfers from rural West Virginia hospitals for patients' age, gender, race and primary health insurance, the diagnosis and desired specialty service. We compared patients who were not transferred. For each transfer we collected data on the reason for transfer, the availability of beds of the appropriate acuity level as well as the availability of the relevant specialty at the time of transfer.

\section{Principal Findings}

Transferred patients were more likely than non-transferred patients to be younger, severely ill and diagnosed with acute coronary syndrome. The relevant specialist was available at the transferring hospital in 6 out of 30 transfers. Beds were available in all cases.

\section{Conclusions}

This pilot study provides an agenda for future research into the decision to transfer patients for acute care from rural hospitals.

\section{Keywords}

Inter-hospital transfers, acute care, rural

\section{Introduction}

According to the Healthcare Cost and Utilization Project, approximately 1.5\% of patients presenting to emergency departments in the United States in 2009 were transferred to another hospital for short term acute care. ${ }^{1}$ The authors cited a corresponding figure for hospitals in rural United States that was twice as high. That rural acute care inter-hospital transfers warrant particular study was highlighted in the findings of a 2006 national panel of academic emergency medicine physicians. ${ }^{2}$ The panel earmarked rural emergency care as an area of improvement, calling for more research in rural settings in partnership with academic medical centers regarding the transfer of patients from local hospitals lacking needed specialty resources.

In this pilot study we traveled from an academic medical center to surrounding West Virginia (WV) rural hospitals to conduct on-site retrospective chart reviews examining acute care patient transfers. Our aim was to document the characteristics of acute care patient transfers from these hospitals and how the transferees differed from patients with similar diagnoses who were not transferred. Our ultimate goal was to guide future research into the factors influencing interhospital transfers in rural WV. 


\section{Methods}

\section{Hospital Selection}

We obtained approval for the project from our institution's Institutional Review Board (IRB). Using a database of all hospitals in West Virginia maintained by the Office of Health Facility Licensure and Certification (OHFLAC) at WV Department of Health and Human Resources and using Rural-Urban Commuting Area Codes (RUCAs) to define rural status we constructed a list of rural WV hospitals within approximately 3 hours' driving time from our institution. We restricted our list to this driving radius because our resources were limited in this pilot project. We excluded Critical Access Hospitals (CAH) since they are required to transfer all patients needing inpatient care except those who can reasonably be expected to be discharged within 96 hours of admission. Therefore, the decision to transfer or not transfer occurs in a distinctive context in these hospitals.

\section{Hospital Participation Recruitment}

We employed a multi-phase recruitment strategy. First, we made phone contact with each hospital's administration representative in order to arrange a personal visit with the chief executive officer (CEO) to request participation in the study. At our meeting we provided a packet of written information that included documents from our IRB application packet as well as the IRB approval letter. About 1 week later, we made follow-up contact with the CEO by phone or email and continued to maintain communication until the administrator had reached a decision regarding his or her hospital's participation. Once we received a signed site permission letter from the CEO, we made arrangements to visit the hospital again for data collection. In one instance where the rural hospital had its own IRB, we also obtained approval from that board before the site visit.

\section{Data Collection}

The hospital's medical records departments pulled the charts of the 10 most recently transferred patients who were over the age of 18 but who were not transferred for obstetric and traumarelated care. We extracted the following de-identified data from each patient chart: age, gender, race, primary health insurance, transfer diagnosis and desired specialty service. In addition, we sorted each transferred patient according to whether or not we judged them to be severely ill. We used disease-specific criteria for severity for each of the following conditions: acute coronary syndrome, acute kidney injury or failure, gastrointestinal bleeding, pneumonia, pulmonary embolus, respiratory failure, sepsis, stroke and seizures. We based our criteria, for most conditions, on established risk stratification scales such as Thrombolysis in Myocardial Infarction (TIMI) risk scores for acute coronary syndrome, National Institutes of Health Stroke Scale (NIHSS) for stroke, RIFLE staging for acute kidney failure, simplified Pulmonary Embolism Severity Index (PESI) for pulmonary emboli and Pneumonia Severity Index (PSI) for community acquired pneumonia. In the remaining instances we applied clinical judgment based on usual and reasonable medical knowledge and practice, for example designating seizures as severe only if they met criteria for status epilepticus.

For each patient with a given transfer diagnosis we reviewed the charts of 2 patients with the same diagnosis who were seen at the hospital in the same time period (usually spanning a month) 
but who were not_transferred. The same inclusion and exclusion criteria were applied to the selection of these patients as to the selection of the transferred patients. We extracted the same data from these charts as from the charts of patients who were transferred and made the same assessment of disease severity. In some cases, there was only 1 appropriate corresponding nontransferee.

We also noted, from the hospital administration's records, relevant specialist availability on the date of each patient transfer and whether or not the hospital was at full bed capacity at the time. In those cases in which critical care was required, we recorded whether beds specifically designated for critical care were available.

\section{Data Analysis}

All data were analyzed using Stata 13 (College Station, TX). We used student t-tests to compare continuous variables between the group of transferred patients and the group of comparable patients who were not transferred. For comparisons involving categorical nominal data we applied the Pearson $\mathrm{Chi}^{2}$ test.

\section{Results}

Of the 12 transferring hospitals that met our selection criteria we had to omit 2 because they were in the process of being acquired by larger institutions and their leadership structure was in flux. 4 of the 10 hospital administrators we contacted ultimately agreed to participate in our project. The 6 hospital administrators who declined to participate either did not return our calls at all or cited having other more pressing, unspecified priorities. Data regarding the hospitals are presented in Table 1.

Table 1: Hospital Characteristics

\begin{tabular}{|l|l|l|l|l|}
\hline & Participated? & Bed capacity & Population $\S$ & Travel time* \\
\hline 1 & Yes & 70 & 4,110 & 2.5 \\
\hline 2 & Yes & 53 & 3,572 & 2.0 \\
\hline 3 & Yes & 173 & 17,656 & 2.0 \\
\hline 4 & Yes & 229 & 17,656 & 2.0 \\
\hline 5 & No & 122 & 3,830 & 2.5 \\
\hline 6 & No & 210 & 6,432 & 2.5 \\
\hline 7 & No & 65 & 2,406 & 3.0 \\
\hline 8 & No & 51 & 5,639 & 2.5 \\
\hline 9 & No & 240 & 10,447 & 2.5 \\
\hline 10 & No & 129 & 1,779 & 1.5 \\
\hline
\end{tabular}

$\S$ Population of town in which hospital is located according to 2010 U.S. Census

* Travel time from our academic medical center rounded to nearest quarter hour.

We examined the 40 patient transfers in different ways. The reason for transfer was most frequently for cardiac care (52.5\%) or for critical or higher level of care (20\%) (Table 2). 
Table 2: Reason for inter-hospital transfers and their frequency

\begin{tabular}{|l|l|}
\hline $\begin{array}{l}\text { Reason for transfer } \\
\text { (specialty sought) }\end{array}$ & $\begin{array}{l}\text { No. of } \\
\text { patients (\% of } \\
\text { column) }\end{array}$ \\
\hline Cardiology & $21(52.5)$ \\
\hline $\begin{array}{l}\text { Critical/higher } \\
\text { level care }\end{array}$ & $8(20.0)$ \\
\hline Patient request & $3(7.5)$ \\
\hline Neurology & $3(7.5)$ \\
\hline Psychiatry & $3(7.5)$ \\
\hline Pulmonology & $1(2.5)$ \\
\hline Hematology & $1(2.5)$ \\
\hline TOTAL & $40(100)$ \\
\hline
\end{tabular}

Acute coronary syndrome (ACS) was the most common transfer diagnosis accounting for over half of the transfers (Table 3 ).

Table 3: Transfer diagnosis by frequency

\begin{tabular}{|l|l|}
\hline Diagnosis & $\begin{array}{l}\text { Number of } \\
\text { transferred } \\
\text { patients } \\
(\% \text { group) }\end{array}$ \\
\hline Acute coronary syndrome & $23(57.5)$ \\
\hline Venous thromboembolism & $3(7.5)$ \\
\hline GI Bleeding & $1(2.5)$ \\
\hline Sepsis & $1(2.5)$ \\
\hline Syncope & $1(2.5)$ \\
\hline Altered mental status & $2(5)$ \\
\hline Stroke & $3(7.5)$ \\
\hline Renal failure & $1(2.5)$ \\
\hline Malaise & $2(5.0)$ \\
\hline Limb pain & $1(2.5)$ \\
\hline Dyspnea & $0(0.0)$ \\
\hline Biliary colic & $1(2.5)$ \\
\hline Thoracic aortic aneurysm & $1(2.5)$ \\
\hline TOTAL & $40(100)$ \\
\hline
\end{tabular}

Appropriate hospital beds were always available at the transferring hospital at the time of transfer. The desired specialist was available at the transferring hospital in as many as $20 \%$ of those 30 transfer cases for which this data was available. 
We compared the group of 40 transferred patients with a group of 69 non-transferred patients with respect to age, gender, race, insurance status, diagnosis and severity of illness. The groups were racially identical, all but 1 patient being white. Approximately $50 \%$ of both groups of patients were Medicare beneficiaries with Medicaid and private insurance accounting for approximately equal portions of the remainder in both groups. The statistically significant differences we identified were that transferred patients were more likely than their nontransferred counterparts to be male, younger, severely ill and to have the diagnosis of ACS. (Table 4)

Table 4: Statistically significant ${ }^{\mathbb{I}}$ differences between transferred and non-transferred patients

\begin{tabular}{|l|l|l|l|l|}
\hline & $\begin{array}{l}\text { Mean age in } \\
\text { years (standard } \\
\text { deviation) }\end{array}$ & $\begin{array}{l}\text { Male gender- } \\
\% \text { of group }\end{array}$ & $\begin{array}{l}\text { Severe disease- } \\
\% \text { of group }\end{array}$ & $\begin{array}{l}\text { ACS diagnosis- } \\
\% \text { of group }\end{array}$ \\
\hline $\begin{array}{l}\text { Non- } \\
\text { transferred } \\
\text { patients }\end{array}$ & $63.1(15.6)$ & 42.0 & 52.2 & 29 \\
\hline $\begin{array}{l}\text { Transferred } \\
\text { patients }\end{array}$ & $54.7(14.0)$ & 65 & 80.0 & 57.5 \\
\hline P-value & 0.006 & 0.021 & 0.004 & 0.003 \\
\hline
\end{tabular}

II $\mathrm{P}<0.05$

\section{Discussion}

This study yielded some expected findings. Unsurprisingly, patients with the diagnosis of ACS were more likely to be transferred than those with any other condition. The prominent role of percutaneous coronary intervention (PCI) in the management of both ST-elevation myocardial infarction (STEMI) and non-STEMI ACS coupled with the limited availability of PCI-capable rural hospitals warrants this frequency. A 2014 University of Minnesota Rural Health Research Center Policy Brief analyzing patient transfers from rural emergency departments also found that cardiovascular diagnoses predominated. ${ }^{3}$ Similarly, it is not surprising that severely ill patients were more likely to be transferred than those with the same diagnosis who were not severely ill.

However, other findings were not as easily explained confirming the need for further research to better understand acute care rural inter-hospital transfers. Our data showed that younger patients tended to be transferred more often than older ones. This finding, previously noted at our institution, ${ }^{4}$ has also appeared in other studies: in patients with systemic lupus erythematosus, ${ }^{5}$ acute myocardial infarction ${ }^{6,7}$ and acute renal failure. ${ }^{8}$ Admittedly, other comparisons between transferred and non-transferred critically ill patients have not shown that transferred patients were generally younger. ${ }^{9,10}$ However, these studies were conducted in a different milieu from our own, being conducted in a large tertiary care referral center or in the United Kingdom, respectively. It is possible that the finding that older patients are less likely to be transferred is a result of older, sicker patients being less desirous of transfer than younger ones. However, Basu's study of elderly New York residents has demonstrated that this dynamic is complex in that severity of illness tended to prompt even the elderly to desire transfer. ${ }^{11}$ 
Even more strikingly, our study identified patients who were transferred from rural hospitals for specialty care that was apparently available at the transferring hospital at the time of transfer.

The 2013 study conducted at our institution had also noted this occurrence at a similar frequency $(24.6 \%) .{ }^{4}$ In the earlier study, the locus of research was the academic referral center and the principal investigator made telephone calls to the administrative offices at the rural referring hospital inquiring about the presence of the relevant specialties during the relevant time period. In this study, we sought greater accuracy by inquiring in person at the rural referring hospital and referring to physician call schedules for specific dates. Exactly why referring rural providers made the decision to transfer patients for specialist care when it was apparently available at their hospitals is unclear. Qualitative research methods might be helpful in exploring this question.

The most important limitation of this study was its small size. There were two reasons for this. We had limited person-hours available and so our study was designed to be a pilot project. For this reason, we sampled a relatively small number of charts at each hospital. The study's size was further diminished because we were unable to recruit more hospitals. In most cases we either did not receive a reason for refusal or did not receive a response at all. A few administrators cited other more pressing administrative issues. It would be worthwhile to systematically explore the attitudes of hospital administrators toward hospital transfers and toward research conducted on this subject by external researchers.

An additional limitation of our study was that we did not examine patient outcomes. This would have required engaging the receiving facilities to which the patients were transferred, a significant logistical complexity for which we did not have the resources.

\section{Conclusion}

The findings of this study that younger rather than older patients were more likely to be transferred and that patients were sometimes transferred for specialty care that was available at the referring hospital are notable. The validity of these findings are weakened by the study's small size and scope. These limitations notwithstanding, this small pilot study has provided a basis for further research into why and how hospital providers in rural West Virginia choose to transfer patients for acute care. 


\section{References}

1. Kindermann D, Mutter R, Pines JM. Emergency department transfers to acute care facilities HCUP Statistical Brief \#155. 2009. Available at http://www.hcup-us.ahrq.gov/reports/statbriefs/sb155.pdf [Accessed on July 30, 2016].

2. Handel DA, Sklar DP, Hollander JE et al. Executive Summary: The Institute of Medicine report and the future of academic emergency medicine and Association of Academic Chairs in Emergency Medicine panel: Association of American Medical Colleges Annual Meeting, October 28, 2006. Academic Emergency Medicine 2007;14: 261-267.

3. Casey M, McCullough J, Krieger R. University of Minnesota Rural Health Research Center. Which Medicare Patients Are Transferred from Rural Emergency Departments? Policy Brief June 2014. Available at: http://rhrc.umn.edu/2014/06/which-medicare-patients-are-transferred-from-rural-emergencydepartments/ [accessed on July 29, 2016].

4. Nair D, Gibbs MM. Inter-hospital transfers from rural hospitals to an academic medical center. West Virginia Medical Journal.2013;109:44-49.

5. Ward MM, Odutola JJ. Inter-hospital transfers of patients with systemic lupus erythematosus: characteristics, predictors and outcomes. Journal of Rheumatology. 2006; 33(8):1578-1585.

6. Westfall JM, Kiefe CI, Weissman NW et al. Does interhospital transfer improve outcome of acute myocardial infarction? A propensity score analysis from the Cardiovascular Cooperative Project. BMC Cardiovascular Disorders. 2008;8:22. doi: 10.1186/1471-2261-8-22.

7. Muus,KJ, Knudson AD, Klug MG, Wynee J. In-hospital mortality among rural medicare patients with acute myocardial infarction: the influence of demographics, transfer, and health factors. Journal of Rural Health.2011; 27(4):394-400.

8. Kudlow P, Burns KEA, Adhikari NKJ, et al. Inter-hospital transfers and outcomes of critically ill patients with severe acute kidney injury: a multicenter cohort study. Critical Care. 2014;18:513. doi: 10.1186/s13054-014-0513-1.

9. Seferian EG, Afessa B, Gajic O, Keegan MT, Hubmayr RD. Comparison of community and referral intensive care unit patients in a tertiary medical center: evidence for referral bias in the critically ill. Critical Care Medicine. 2008; 36(10):2779-2786.

10. Barratt H, Harrison DA, Rowan KM, Raine R. Effect of non-clinical inter-hospital critical care unit to unit transfer of critically ill patients: a propensity-matched cohort analysis. Critical Care. 2012; 16(5): R179. doi: $10.1186 / \mathrm{cc} 11662$.

11. Basu J. Severity of illness, race, and choice of local versus distant hospitals among the elderly. Journal of Health Care for the Poor and Underserved. 2005;16: 391-405. 